\title{
Fios Soltos da Rede de Proteção dos Direitos das Crianças e Adolescentes
}

\author{
Ana Cristina Serafim da Silva ${ }^{1}$ \\ ${ }^{1}$ Universidade Federal do Tocantins, TO, Brasil.
}

\author{
Maria de Fátima Pereira Alberto ${ }^{2}$ \\ ${ }^{2}$ Universidade Federal da Paraíba, PB, Brasil.
}

\begin{abstract}
Resumo: Este artigo tem como objetivo saber como vem se constituindo a Rede de proteção dos direitos das crianças e dos adolescentes a partir das práticas dos atores sociais. Participaram do estudo dez atores sociais que atuam na Rede de proteção dos direitos da criança e do adolescente numa cidade de porte médio no norte do Tocantins. Optou-se por uma abordagem qualitativa, utilizando-se da entrevista semiestruturada para coleta de dados; e para análise dos dados, a Análise de Conteúdo de Bardin. Dentre os principais resultados, percebeu-se uma Rede desestruturada, caracterizada pela falta de articulação entre as instituições que a compõem, além da falta de capacitação e conhecimento dos atores sociais, no que se refere inclusive a aspectos legais. Mesmo com todo avanço na legislação, os direitos positivados na lei não são suficientes para que haja a proteção da criança e do adolescente, pois as práticas das instituições e dos atores sociais não consideram a condição peculiar do desenvolvimento, nem o princípio da dignidade humana, visto que são práticas baseadas em paradigmas higienistas, que servem como mecanismos de controle em detrimento da política de proteção integral.
\end{abstract}

Palavras-chave: Rede, Infância e Adolescência, Proteção dos Direitos.

\section{Loose Yarn of the Network for the Protection of Children and Adolescents' Rights}

\begin{abstract}
This paper aims to know how the Network for the protection of the rights of children and adolescents has been constituted based on the practices of social actors. Ten social actors working in the Network for the Protection of the Rights of Children and Adolescents participated in the study in a medium-sized city in the north of Tocantins. We chose a qualitative approach, data were collected by means of semi-structured interviews and analyzed using Bardin's Content Analysis. The speeches of the social actors reveal a destructured Network marked by a lack of articulation between the institutions that make it up, as well as a lack of training and knowledge, including in terms of legal aspects, by social workers. Despite the progress in legislation, the rights provided by law do not sufficiently protect children and adolescents, because the practices performed by institutions and social actors do neither take into account the specific condition of development, nor the principle of human dignity, given the fact that these practices are based on hygienist paradigms that are used as control mechanisms, to the detriment of the Integral Protection policy.
\end{abstract}

Keywords: Network, Childhood and Adolescence, Protection of Rights. 


\title{
Hilos Sueltos de la Red de Protección de los Derechos de los Niños y Adolescentes
}

\begin{abstract}
Resumen: Este artículo tiene como objetivo saber cómo se viene constituyendo la Red de protección de los derechos de los niños y de los adolescentes a partir de las prácticas de los actores sociales. Participaron del estudio diez actores sociales que actúan en la Red de protección de los derechos del niño y del adolescente en una ciudad de tamaño mediano en el norte de Tocantins. Se optó por un enfoque cualitativo, utilizando la entrevista semiestructurada para la recolección de datos; y para el análisis de los datos, el Análisis de Contenido de Bardin. Entre los principales resultados, se percibió una Red desestructurada, caracterizada por la falta de articulación entre las instituciones que la componen, además de la falta de capacitación y conocimiento de los actores sociales, en lo que se refiere incluso a aspectos legales. . A pesar de todo el avanzo en la legislación, los derechos positivos en la ley no son suficientes para que haya la efectiva protección del niño y del adolescente, pues las prácticas de las instituciones y de los actores sociales no consideran la condición peculiar del desarrollo, ni el principio de la dignidad humana, ya que son prácticas basadas en paradigmas higienistas, que sirven como mecanismos de control en detrimento de la política de protección integral.
\end{abstract}

Palabras clave: Red, Infancia y Adolescencia, Protección de los Derechos.

\section{Introdução}

A partir do Estatuto da Criança e do Adolescente (ECA) houve uma modificação nas políticas públicas voltadas para a infância e adolescência, que devem atuar no formato em Rede, com instituições e atores sociais articulados e integrados na garantia e proteção dos direitos desses sujeitos. É objetivo deste artigo saber como vem se constituindo a Rede de proteção dos direitos das crianças e dos adolescentes a partir das práticas dos atores sociais.

Para tanto, faz-se necessário saber que a perspectiva da proteção integral, adotada no final do século XX, contrapõe-se a uma perspectiva de disciplinamento e dominação das crianças perpetuada historicamente, em que se revela uma hegemonia de práticas higienistas, assistencialistas e caritativas voltadas para a infância e a adolescência (Cruz, \& Guareshi, 2012; Faleiros, 2011; Rizini, \& Pillotti, 2011).

Foi em oposição à doutrina da situação irregular que se desenvolveram concepções e movimentos que colocavam a criança e o adolescente como sujeitos de direitos, pela própria Organização das Nações Unidas (ONU). O Brasil adotou a doutrina da proteção integral em sua Lei Maior, a Constituição Federal de 1988, que garante à criança e ao adolescente, com dever do Estado, da sociedade e da família, com absoluta prioridade, o direito à vida, à saúde, à alimenta- ção, à educação, ao lazer, à dignidade, ao respeito, à liberdade, à convivência familiar e comunitária, além de colocá-los a salvo de toda forma de negligência, discriminação, exploração, violência e crueldade (Senado Federal, 1988).

A doutrina de proteção integral foi regulamentada pelo ECA, um instrumento jurídico inovador, que tem como base a concepção de proteção integral, defendida pela ONU na Declaração Universal dos Direitos da Criança de 1959. Sobretudo, o ECA supera o enfoque repressor e assistencialista das leis anteriores e introduz na legislação nacional a concepção de crianças e adolescentes como sujeitos de direitos exigíveis em leis. Além disso, a questão saiu da competência exclusiva dos juízes de menores, por meio da descentralização político-administrativa, restringindo o papel dos estados e ampliando as competências e responsabilidades dos municípios e da comunidade, além de contar com a participação da população por meio de suas organizações representativas (Conselhos Municipais, Estaduais e Nacional dos Direitos da Criança e do Adolescente e Conselhos Tutelares). Esse documento reitera o papel de todos no cuidado com a infância e a adolescência.

Uma das principais funções do Estatuto é precisamente oferecer procedimentos e medidas distintas por suas necessidades e especificidades no tratamento 
de novas emergências humanas e sociais, procurando, dessa maneira, estabelecer outras estratégias e metodologias para proteção dos valores sociais democraticamente estabelecidos na Lei. Entre essas estratégias, temos o Sistema de Garantia de Direito (SGD) da criança e do adolescente e toda uma inovadora Rede institucional, que lhe dá sustentação e legitimidade política fundada em um modo de organização em Redes, baseado no artigo 86 do ECA sobre política de atendimento aos direitos da criança e do adolescente (Oliveira, 2010; Ramidoff, 2007).

O SGD se constitui na articulação e integração das instâncias públicas governamentais e da sociedade civil, na aplicação de instrumentos normativos e no funcionamento dos mecanismos de promoção, defesa e controle para efetivação dos Direitos Humanos da criança e do adolescente nos níveis Federal, Estadual e Municipal. O objetivo é reinventar novas práticas sociais capazes de provocar transformações no âmbito da consciência e da concepção da sociedade em relação à dimensão do público, com vistas à constituição de processos emancipatórios no campo da legislação, das políticas públicas, das organizações e do próprio fortalecimento de um projeto societário, consolidado pela participação, democratização e cidadania.

Dessa forma, o desafio para materialização das políticas públicas, e com isso a garantia dos direitos das crianças e dos adolescentes passa pelo atendimento das políticas numa perspectiva de Rede. Entende-se o conceito de Rede como um tecido de relações que são estabelecidas a partir de uma finalidade em comum e se interconectam por ações em conjunto (Rizzini, 2006). A Rede é uma ferramenta das políticas públicas cujo objetivo é proteger os direitos das crianças e dos adolescentes, formada pelos atores sociais das várias instituições engajadas no mesmo propósito. Para Rizzini (2006), uma Rede integrada e articulada deve estar ligada com os diversos setores das políticas públicas (saúde, educação, justiça, entre outros), pois, dessa forma, ofertará um atendimento completo à criança, ao adolescente e a suas famílias.

No entanto, diversos autores (Alberto, Silva, Gomes, Santana, \& Soares, 2012; Aragão, 2011; Faraj, \& Siqueira, 2012; Faraj, Siqueira \& Arpini, 20016; Habigzang, Azevedo, Koller, \& Machado, 2006; Macedo, \& Conceição, 2017; Macedo, Pessoa, \& Alberto, 2015; Morais, Sales, Rodrigues, \& Oliveira, 2016; Oliveira, 2010; Oliveira \& Yamamoto, 2014; Scisleski, 2006;
Silva, \& Pereira, 2013) corroboram com a assertiva de que as políticas públicas da infância e adolescência vêm trabalhando de forma desarticulada, com problemas na qualificação de seus atores sociais, o que causa prejuízo na implementação de políticas públicas que garantam os direitos assegurados pela legislação em vigor, compromete a superação de situações de violência e a efetivação dos direitos das crianças e dos adolescentes.

Segundo Behring e Boschetti (2011), a assistência social é a política que tem mais sofrido para se materializar como política pública e precisa superar algumas características históricas, como: a morosidade na sua regulamentação como direito; a abrangência, visto que os programas e serviços atingem entre $15 \% \mathrm{e}$ $25 \%$ da população que deveria ter acesso aos direitos; e a ênfase nos programas de transferência de renda, de caráter compensatório.

Para Yamamoto e Oliveira (2010), os avanços alcançados nas políticas sociais, a despeito da manifestação da priorização da área social, ainda são considerados mínimos. Para alguns autores (Behring, \& Boschetti, 2011; Oliveira, \& Yamamoto, 2014), é mantido o caráter compensatório, seletivo, fragmentado e setorizado da política social brasileira, como desdobramentos e até mesmo respostas e formas de enfrentamento para a desigualdade dentro dos marcos do modo de produção capitalista. Há um aprofundamento das desigualdades sociais, constituindo-se o empobrecimento dos trabalhadores e de suas famílias, e, para amenizar essa situação, o Estado tem priorizado programas de cunho assistencialista e compensatório, que não atendem a todos e são voltados principalmente para os grupos mais pobres e vulneráveis (Cruz, \& Guareschi, 2012; Yamamoto, \& Oliveira, 2010).

Nesses termos, Marques (2006) chama a atenção para a "insistência" em uma política social que fragmenta suas ações, nas políticas que se caracterizam por serem centralizadas, verticalizadas e descontinuadas, com sobreposição de ações, sem a participação da coletividade. Diante disso, é necessária a construção de políticas sociais verdadeiramente públicas, que incluam os diversos saberes envolvidos em torno do problema a ser debatido pela comunidade interessada e com práticas horizontalizadas por meio de espaços de conservação que possibilitem romper com as estruturas hierarquizadas e lineares. 
Nesses termos, a Rede é uma ferramenta das políticas públicas, que inclui os diversos saberes, cujo objetivo é proteger os direitos das crianças e dos adolescentes, formada pelos atores sociais das várias instituições engajadas no mesmo propósito. Quando se fala na flexibilidade e dinamicidade da Rede, implica dizer que ela não é fixa, cristalizada, e que as informações são repassadas na própria dinâmica da Rede. No entanto, Rizzini (2006) chama a atenção para essa renovação, principalmente no sentido da própria formação dessa Rede e dos atores sociais, para que, a cada mudança de administração, não se modifique a estrutura da própria Rede e os atores que a compõem, pois isso pode prejudicar o andamento e a articulação de uma Rede que já estava estabelecida.

Conforme Marteleto (2001), a Rede só tem sentido se houver interação entre todos os atores sociais que fazem parte das instituições, já que uma Rede não se reduz a uma simples soma de relações entre os atores sociais, e a sua forma exerce influência sobre cada relação. Diversas pesquisas (Faraj, \& Siqueira, 2012; Faraj, Siqueira \& Arpini, 2016; Macedo, Pessoa \& Alberto, 2015; Morais, Sales, Rodrigues, \& Oliveira, 2016) abordam a importância do atendimento em rede para o enfrentamento da violência contra crianças e adolescentes e proteção dos direitos, como também permite repensar formas instituídas de atuação e buscar outras que rompam com práticas tradicionais que muito mais violam direitos do que protegem (Reis, \& Guareschi, 2016).

Outro fator, apontado por Ude (2008), para que haja efetivação da rede é atentar para as demandas coletivas e individuais dos atores sociais, uma vez que alguns baseiam suas práticas a partir de conceitos prévios, que podem proteger, mas que também podem silenciar a violência praticada contra as crianças e os adolescentes (Schek, et al., 2018). Esse é um dos aspectos encontrados em pesquisa desenvolvida por Macedo, Pessoa e Alberto (2015), cujos profissionais que atuavam na Política de Assistência Social tinham uma atuação pautada numa concepção naturalizante, universalista e descontextualizada sobre a infância e adolescência, fazendo o jogo de modelos que serializam e fixam identidades (Macedo, \& Dimenstein, 2012). Tal fato leva a um comprometimento das ações dos atores sociais que fazem parte da Rede, pois há um distanciamento da realidade concreta da infância e adolescência usuária da Política de Assistência Social, limitando a contribuição no que tange à efe- tivação dos direitos desses sujeitos (Macêdo, Pessoa \& Alberto, 2015). Somado a isso, o desconhecimento jurídico e técnico também compromete a solução dos casos que chegam até as instituições, principalmente no que concerne aos encaminhamentos e procedimentos mais adequados a cada caso (Faraj, Siqueira, \& Arpini, 2016; Macedo, \& Conceição, 2017).

Com a vigência do ECA, a sociedade, e isso inclui também os atores sociais, precisa reestruturar-se a fim de atender às novas normas embasadas no princípio de que a criança é pessoa em desenvolvimento, é sujeito de direitos e é prioridade absoluta. As crianças e os adolescentes passam a ser considerados e respeitados como seres em formação, sujeitos de direitos como qualquer outro cidadão, e têm seus direitos fundamentais garantidos pelo referido Estatuto. Este representou um grande passo no exercício da democracia, garantindo às crianças direitos à liberdade, à participação e ao bem-estar na sociedade (Faraj, Siqueira \& Arpini, 2016; Rosemberg, \& Mariano, 2010).

No entanto, mesmo com toda essa conjuntura, de conselhos em nível federal, estadual e municipal, e a organização das instituições em Rede, em que propõe o cumprimento da legislação sobre os direitos das crianças e dos adolescentes, ainda não temos, na prática, a proteção das crianças e dos adolescentes sendo assistidos em todos os âmbitos.

Se pensarmos nos espaços de intervenção social como lugares onde as instituições poderiam discutir e reformular as políticas, temos, no cenário atual, um lugar que deixa evidente as contradições nos discursos ditos igualitários, na medida em que são produzidas e difundidas linhas conservadoras e novas práticas instituídas. E, embora a proposta contida no ECA seja abrangente, a gestão política é articulada por interesses específicos, dando vários sentidos à lei.

\section{Aspectos metodológicos}

Trata-se de um estudo exploratório de caráter qualitativo. O contexto escolhido para o desenvolvimento do estudo foi uma cidade de porte médio no norte do Tocantins que apresentava instituições que faziam parte dos três eixos do SGD (Defesa, Promoção e Controle). As instituições foram identificadas pelo Conselho Municipal dos Direitos das Crianças e dos Adolescentes (CMDCA) da cidade como fazendo parte do SGD. Das 14 instituições indicadas, dez delas concordaram em participar da pesquisa, foram elas: Conselhos Tutelares I e II, o Ministério Público, a Dele- 
gacia da Infância e Juventude, a Defensoria Pública, o Centro de Referência Especializado de Assistência Social (Creas), o Centro de Referência de Assistência Social (CRAS), o Centro de Atendimento Psicossocial (CAPS) e duas Casas de Acolhida. O agendamento do horário e do local das entrevistas foi por telefone, considerando a disponibilidade do ator social. Todas as entrevistas foram realizadas no ambiente de trabalho, com o ator social responsável ou que se encontrasse na instituição.

Utilizou-se como técnica de coleta de dados a entrevista semiestruturada, cujo roteiro temático foi composto por questões sobre a formação e a carreira do Ator Social até o momento dado; a formação específica para trabalhar com crianças e adolescentes; procedimentos adotados para os casos de violação dos direitos das crianças e dos adolescentes que chegam até a instituição; as práticas da instituição que garantem a efetivação de direitos de crianças e adolescentes; e a existência do formato em Rede das instituições e seu funcionamento.

Com entrevistas gravadas, estas foram transcritas fielmente às falas dos entrevistados e analisadas de acordo com a análise de conteúdo, mais especificamente, por meio da técnica de Análise Temática de Bardin (2010). Em seguida, foi realizada uma leitura flutuante de todo o material transcrito e impresso. Posteriormente foi realizada a tabulação, que consistiu numa agregação das temáticas semelhantes. Da codificação emergiram as categorias representativas dos núcleos de sentido. As categorias que surgiram foram: A Rede de proteção desarticulada; As práticas higienistas e a lógica menorista dos atores sociais e das instituições; e As políticas públicas e os direitos de proteção.

Para esta pesquisa, foram adotados todos os passos determinados pela Resolução no 466, de 12 de dezembro de 2012, do Conselho Nacional de Saúde que regulamenta a pesquisa em seres humanos. Com aprovação do projeto de pesquisa pelo Comitê de Ética em Pesquisa, sob o número CAAE 17147613.7.0000.5188.

\section{Resultados}

Sobre a formação dos dez atores sociais entrevistados, oito tinham curso superior, um estava cursando no momento da pesquisa e o outro tinha ensino médio. Dentre os cursos superiores, quatro atores sociais tinham graduação em Direito, dois atores sociais tinham formação em Pedagogia, um em Geografia, um em Psicologia e um em Serviço Social. Apresentavam tempo de formação que variava de 20 anos a um ano; já o tempo de trabalho na instituição onde foi realizada a pesquisa variava de 9 anos a 9 meses, com prevalência de um ano na referida instituição.

Os atores sociais entrevistados relataram que não tiveram nenhuma formação específica ou direcionamento durante a graduação para a área da infância e adolescência, e os conhecimentos relacionados à infância e adolescência, só tiveram de forma supérflua durante a graduação.

Além dos aspectos biossociodemográficos, a partir das falas dos atores sociais foram agrupadas as categorias representativas: A Rede de proteção desarticulada; As práticas higienistas e a lógica menorista dos atores sociais e das instituições; e As políticas públicas e os direitos de proteção.

\section{A Rede de proteção desarticulada}

A partir dos resultados obtidos pelas entrevistas, sobressai um conceito de Rede, em que esta aparece como se fosse uma instituição responsável pelo acompanhamento dos casos encaminhados, visto que a demanda que chega até as instituições é grande e os atores sociais não conseguem realizar o acompanhamento de todos os casos. Conforme fala a seguir: “[...] São muitos atendimentos, então, assim, não dá pra você dar muita atenção. Por isso que a gente tem que encaminhar pra rede. Por isso é que a rede tem que acompanhar, porque o nosso não dá tempo de ficar acompanhando ali no dia a dia” (Ator Social 2). Outras falas também conceituam a existência da Rede porque os atores sociais buscam estar em conexão um com outro, "há uma Rede em questão de harmonia" (Ator Social 8), como também há quem considere a existência da Rede porque os outros atores sociais que compõem a Rede não dificultam o acompanhamento de "usuários" [sic] da instituição; nesse sentido, os atores sociais afirmam que ela funciona. Há também quem afirme que a Rede é importante, e, se não fosse a atuação da Rede, eles não teriam como fazer nada.

No que se refere à funcionalidade da Rede, as falas abordam a questão da sua existência, mas a maioria afirma que esta não funciona. Entre as causas, estão a falta de comunicação entre as instituições, a indecisão sobre a quem recorrer, a falta de conhecimento de algumas instituições como 
fazendo parte da Rede, a divergência de conceitos sobre a Rede, já que "nem todos falam a mesma língua" [sic] (Ator social 10). Dessa forma, a existência de uma Rede fica comprometida, considerando que, para que se tenha uma Rede, é necessário a comunicação e o entendimento e que todos partilhem do mesmo código.

Quanto aos atores sociais, não há formação para trabalhar na área da defesa e proteção dos direitos da infância e da adolescência. Apenas dois atores sociais já trabalhavam anteriormente na política da assistência social. E uma das principais demandas que surgiu a partir das falas foi a capacitação e formação para que pudessem, de fato, consolidar as políticas voltadas para a infância e adolescência.

\section{As práticas higienistas e a lógica menorista dos atores sociais e das instituições}

Foram identificados dois tipos de práticas realizadas pela Rede: uma que se refere ao que está prescrito como norma operacional da instituição, referindo-se às funções que cada instituição tem; nesse caso, cada instituição teria uma função prescrita diferente da outra, embora todas tenham como principal objetivo a efetivação dos direitos da criança e do adolescente. A outra prática identificada vai além do que está prescrito, e envolve as concepções do próprio Ator Social. Entre as diversas práticas, as falas relatam a fiscalização de ambiente identificado como violentador, o fazer acontecer para garantir o direito, além do uso de remédios para dopar crianças/adolescentes, elaboração de relatórios para internação, entre outros. A fala a seguir retrata uma dessas práticas:

A gente já pegou caso aqui de um menino, que a gente demorou quase um ano pra conseguir que a juíza interne ele, né [sic]. [...] Por vários delitos mesmo! Teve um mesmo que a gente chegou no ponto, eu fiz um relato pra juíza, "ó, se você não internar esse aqui, eu num vou fazer mais nada não! Ele tem que ser punido!” Por quê? Porque que... você, que foi agredida por aquele menor, com ele não acontece nada, e com você?! Ele pode lhe agredir, e você não pode fazer nada? A juíza daqui, ela é muito difícil de querer internar uma criança na casa de detenção [...]. A lei tem várias falhas, essa é uma delas (Ator Social 1).
Outra prática que chamou atenção foi o uso de medicamentos em algumas instituições para dopar as crianças e os adolescentes, cuja justificativa era a fuga das crianças e dos adolescentes da instituição, como também para poder acalmá-los e evitar que usassem drogas. É um dado preocupante, já que somente uma instituição possuía uma equipe multidisciplinar, o que equivale a dizer que as instituições não têm profissionais capacitados para tal procedimento.

Em meio a essas práticas que encontram respaldo nos códigos anteriores, também existem práticas de alguns atores sociais que vão além do prescrito, que “vão em busca do vulnerável" (Ator social 5), ir além das paredes da instituição, designada por busca ativa, que é uma ação fundamental para o reconhecimento das demandas. Esse trabalho fora da instituição também é um trabalho que compete a ele enquanto ator social para que sejam efetivadas as políticas públicas relacionadas à infância e à adolescência. O que se percebe é que há tentativas de costurar a Rede, tecer os fios para que haja um nó, mas também há processos de dificuldade.

Já no que se refere às práticas prescritas da instituição, a partir dos resultados apresentados, pode-se perceber que existe uma dinâmica entre as instituições que compõem a Rede, e cada ator social tem procurado cumprir sua função, dentro do que é estabelecido pelos documentos legais, como as normas adotadas nas resoluções do Conselho Nacional dos Direitos da Criança e do Adolescente - Conanda (Resolução $n^{\circ} 113,2006$ ), assim como no ECA (Lei no 8.069, 1990), nas Normas Operacionais Básicas (NOB) e nos Manuais elaborados pelo Ministério do Desenvolvimento Social que abordam as funções de cada instituição.

\section{As políticas públicas e os direitos de proteção}

De acordo com as falas, os encaminhamentos geralmente são feitos quando se nota a necessidade da atuação de outro profissional, ou quando o ator social acredita que vai ter algum aproveitamento, ou ainda nos casos de dependência química.

A fala abaixo retrata bem essa questão:

Nos casos que a gente acredita que vai ter algum aproveitamento, sim. Ou então uma criança que tá de alguma forma dependente químico, ou bebida alcoólica, encaminha para o CAPS, que vai 
fazer um atendimento controlado, só que a gente não acredita muito, eu posso falar em nome da maioria aqui, do CAPS porque é um tratamento alternativo, não é obrigatório. O "menor" tem que ir até lá, pra tomar o medicamento, entendeu? Pra se controlar. O que que acontece? Vai um, dois, três dias e acabou-se. São raros os casos que consegue se medicar apenas com o CAPS, mas acontece. É uma solução, é uma saída (Ator Social 1).

Outra questão levantada pelos atores sociais foi o não retorno dos encaminhamentos feitos à Rede, a contrarreferência, que é o feedback para a instituição demandante do atendimento, da resolutividade dos casos encaminhados. Mais uma vez, a Rede aparece aqui como se fosse outra instituição responsável pelo recebimento de casos, e a busca por informações, quando do encaminhamento dos casos, não é função da instituição demandante, conforme as falas. Outro aspecto destacado nas falas foi com relação à infraestrutura, que não é adequada para o atendimento, dificultando inclusive, o acesso e o atendimento a crianças e adolescentes que tinham, por exemplo, dificuldade de locomoção.

\section{Discussão}

Percebe-se, no que se refere à concepção dos atores sociais sobre Rede, que não existe um conceito único, mas várias definições. Em tais definições, a Rede aparece como se fosse uma instituição que tivesse a função de fazer o acompanhamento dos casos encaminhados, corroborando os achados de vários autores (Marteleto, 2001; Ude, 2008). Tal aspecto também reflete o conflito que Marteleto (2001) afirma pertencer ao conceito de Rede, em que aparece o dualismo ator/estrutura. Nesse caso, os dados sugerem uma Rede como uma instituição cristalizada, responsável pelo atendimento dos casos encaminhados, e não como uma forma de funcionamento. Sobre isso, Scisleski e Maracshin (2012), em pesquisa desenvolvida apontam que a simples utilização do termo Rede por parte dos atores sociais sugere-se a existência da mesma e ainda, operadora das políticas públicas e propostas de intervenção. Apesar de todos saberem que existe uma Rede, as práticas dos atores sociais continuam restritas a suas funções dentro da instituição em que atuam.
Os dados revelam uma Rede não integrada e desarticulada, fatores imprescindíveis para a existência de uma Rede conforme Rizzini (2006), de modo que os diversos setores das políticas públicas, tais como saúde, educação, assistência social e justiça, não estão ligados. É a partir da interação entre as diversas instituições que se ofertará um atendimento completo à criança, ao adolescente e a suas famílias, conforme adotado pelo ECA, no seu artigo 86, e pela resolução do Conanda.

Os dados encontrados aqui estão em sintonia com diversas outras pesquisas (Caravieri, \& Avoglia, 2016; Faraj, \& Siqueira, 2012; Macedo, \& Conceição, 2017; Morais et al., 2016; Schek et al., 2018; Silva, \& Pereira, 2013) que apontam uma rede desestruturada, que não consegue manter uma comunicação adequada entre os atores sociais e entre as instituições, o que compromete o serviço disponibilizado e a proteção dos direitos das crianças e dos adolescentes, bem como vai no sentido inverso do que está preconizado nas Normas de Orientação do Sistema Único de Assistência Social (SUAS).

A falta de formação dos atores é um dos fatores que tem comprometido essa efetivação dos direitos das crianças e dos adolescentes, indo contra as determinações do ECA e dos guias desenvolvidos pelo Ministério de Desenvolvimento Social. Diversos autores também encontraram dados sobre a não qualificação dos atores sociais e o trabalho desarticulado nas redes de proteção como um comprometimento das políticas públicas para crianças e adolescentes (Aragão, 2011; Faraj et al., 2016; Habigzanget al., 2006; Macedo \& Conceição, 2017; Oliveira, 2010; Oliveira, \& Yamamoto, 2014; Schek et al., 2018; Scisleski, 2006).

Yamamoto e Oliveira (2010) também apontam para o fato de haver uma alta rotatividade dos profissionais, cujos vínculos são baseados na confiança e não na competência, prejudicando a eficiência do atendimento dessas instituições, tendo em vista a perda de profissionais e, com isso, uma ruptura nessas políticas. Essa rotatividade de profissionais foi uma das questões levantadas pelos atores sociais como prejudiciais ao trabalho; afinal, a cada mudança de governante, mudavam também os atores sociais e com isso, toda a política que estava em andamento. Visto que era necessário um tempo para que cada ator social se adaptasse e tivesse conhecimento sobre a função da instituição em que trabalhava, assim como as suas atribuições dentro dela. 
A partir das entrevistas realizadas nesta pesquisa, percebe-se que a Rede de proteção dos direitos das crianças e dos adolescentes tem tido práticas predominantemente de encaminhamentos para a Rede, não havendo a contrarreferência dos casos encaminhados à Rede e a garantia do reestabelecimento do direito violado, visto que a Rede e as instituições se encontram sobrecarregadas. A precarização e a naturalização desse modelo de Rede não permitem que ela seja um espaço de garantia do direito, visto a Rede não ser um espaço de troca que possa proporcionar a consolidação do que está prescrito.

Diversas pesquisas também apontaram a dificuldade de encaminhamentos e de interação entre os atores sociais e a Rede de proteção dos direitos das crianças e dos adolescentes, com ações fragmentadas, pontuais e isoladas (Faraj, \& Siqueira, 2012; Macedo, \& Conceição, 2017; Macedo et al, 2015; Morais et al., 2016; Schek et al., 2018). Há uma morosidade na articulação da rede, equívocos quanto a abordagem, falta de capacitação dos atores sociais, atrelado a isso, ainda tem as concepções de infância e adolescência em que se baseiam os atores sociais, contrárias as adotadas nos documentos legais atuais.

Esse é um aspecto que Ude (2008) chama a atenção, as diversas práticas dos atores sociais, influenciadas pelas concepções de cada um. Dentre as práticas indicadas, algumas chamaram a atenção pelo fato de sugerirem incongruência com os códigos legais adotados atualmente, como a elaboração de relatórios para internação, e o possível abandono do caso pelo ator social e pela instituição, em decorrência da negação do juiz. Reis e Guareschi (2016), em pesquisa realizada, também encontraram práticas que, embora revestidas de discurso de proteção, eram utilizadas como mecanismos de controle e punição. Para as autoras, a Assistência Social e o Conselho Tutelar têm funcionado como monitoramento das crianças e dos adolescentes pobres, juntamente com suas famílias, e a internação é vista como uma ferramenta de "punição" perante a não eficácia das outras medidas protetivas por parte da rede.

O que se observa é a prevalência de práticas baseadas no Código de Menores, que propõe a internação e a punição como solução, já que essas crianças e esses adolescentes são considerados mais perversos que muitos adultos. Tal prática difere do papel da instituição, que é proteger os direitos das crianças e dos adolescentes.
De acordo com alguns autores (Cruz, \& Guareschi, 2012; Faleiros, \& Faleiros, 2008; Rizzini, 2011), essas propostas de repressão à ociosidade, de recolhimento em colônias correcionais, de suspensão do poder familiar, entre outras, consolidaram-se na primeira legislação específica voltada para os "menores de idade", que foi o Código de Menores de 1927. Tais práticas soam muito contraditórias no contexto do ECA, documento legal que regula a infância e a adolescência no Brasil, adotando a perspectiva da proteção integral, tal como afirmam alguns autores (Faleiros, \& Faleiros, 2008; Lei no 8.069, 1990; Rosemberg, \& Mariano, 2010) que se contrapõem a uma perspectiva de disciplinamento e dominação das crianças perpetuada historicamente. A violência contra crianças e adolescentes esteve presente na história da humanidade desde os mais antigos registros e, nos dias atuais, esse legado ainda persiste, mesmo naqueles espaços que são responsáveis pela efetivação dos direitos.

Destaca-se o uso frequente de expressões baseadas em perspectivas de controle, proteção e práticas higienistas, que apenas servem como mecanismos de controle político do Estado. Ainda temos todo o legado das legislações anteriores que abordavam a correção e prevenção das crianças e adolescentes pobres, além da culpabilização das famílias no que se refere aos cuidados com os filhos. Percebe-se que desde a implantação do ECA (Lei no 8.069, 1990), as funções e características das instituições foram alteradas e têm sofrido adaptações à nova legislação; no entanto, nem todos os atores sociais estão capacitados para olhar a criança ou adolescente como sujeitos de direitos, em que se garante a proteção integral, considerando sua condição peculiar de desenvolvimento (Faraj et al., 2016). E alguns atores sociais ainda têm arraigados valores baseados na doutrina da situação irregular.

No entanto, percebe-se que as instituições que tentavam se articular com outras tinham resultados melhores no que se refere ao atendimento e à proteção dos direitos das crianças e dos adolescentes. Embora não conseguissem funcionar articuladamente em Rede, algumas instituições (CRAS, CREAS) mantinham contato com as outras instituições, seja pelo tipo de serviço oferecido, seja pela necessidade de encaminhamento a outras instituições, ou mesmo pela atuação de alguns atores sociais. Esses dados também foram encontrados por Faleiros e Faleiros (2001), Faraj et al. (2016) e 
Rizzini (2006). Segundo tais autores, há maiores chances de sucesso naquelas instituições que se articulam umas com as outras.

Marteleto (2001) chama a atenção para o fato de que só tem sentido uma Rede se houver interação entre todos os atores sociais que fazem parte dela. E não é só a simples soma de relações entre os atores sociais. Vai mais além: é necessária a interação entre os vários atores.

É preciso pensar nessas práticas dos atores sociais, bem como na formação e capacitação para uma ação efetiva da Rede, atentando para as demandas coletivas e individuais desses atores (Ude, 2008), no sentido de superar as práticas baseadas na doutrina da situação irregular e na perspectiva de controle que muito mais violam do que garantem a proteção de crianças e adolescentes (Macedo, \& Conceição, 2017). É urgente o investimento do Estado em formações e capacitações para que as práticas dos atores sociais possam se basear e se apropriar da atual legislação dos direitos das crianças e dos adolescentes.

O ECA surge como um instrumento jurídico inovador, baseado na concepção de proteção integral, defendida pela ONU na Declaração Universal dos Direitos da Criança (Faleiros, \& Faleiros, 2008). No entanto, os dados não mostram práticas baseadas na concepção de proteção integral, inclusive não se reconhece a especificidade da criança, em razão de sua imaturidade, muito pelo contrário, a criança e o adolescente são considerados responsáveis pelos seus atos, e a proteção é vista como um erro, principalmente no que se refere à condição peculiar do desenvolvimento desses sujeitos, aspecto também encontrado por Rosemberg e Mariano (2010). Tal prática reflete ainda a permanência das legislações anteriores, com um enfoque repressor e assistencialista (Cruz, \& Guareshi, 2012; Faleiros, \& Faleiros, 2008; Rizzini, \& Rizzini, 2004).

Outras pesquisas também confirmam os dados, sobre a dificuldade dos atores sociais na interpretação dos documentos legais, principalmente no que se refere ao entendimento de que as crianças e adolescentes são sujeitos de direitos (Faraj et al., 2016). Os autores chamam a atenção para práticas que podem colocar em risco a vida das crianças e dos adolescentes, ou que mantem o sofrimento esquecido ou mesmo no anonimato (Faraj, \& Siqueira, 2012; Schek et al., 2018). Há uma transferência de responsabilidade entre os atores sociais e instituições pela prote- ção, com falta de registros dos casos que chegam até a instituição.

Tais práticas limitam a atuação dos atores sociais no que concerne a garantia de direitos, ou mesmo anulam outros potenciais para a construção de relações duradouras que promovam atores sociais coletivos e que possam edificar políticas públicas estruturalmente saudáveis.

Destaca-se também o descrédito coletivo, conforme fala do ator social, na resolução dos casos encaminhados às instituições que realizam acompanhamento de dependentes químicos, devido à criança e/ ou adolescente não ficarem internados, sendo visto como um tratamento alternativo, não obrigatório, evidenciando mais uma vez as demandas coletivas e individuais dos atores sociais a que Ude (2008) chama atenção. $\mathrm{O}$ encaminhamento é feito em virtude da crença do ator social de que vai ter algum resultado, ou quando a instituição é obrigada fazer o encaminhamento, tal fato vai contra todo o paradigma de direito preconizado pela Constituição Federal de 1988 e a doutrina de proteção integral adotada pelo ECA. Essas práticas podem indicar ações de caráter paliativo, de cunho assistencialista, conforme Faleiros (2011) assinala, comprometendo, desta forma, o paradigma educativo e de direitos que foi implementado nas políticas para crianças e adolescentes na década de 1980.

Nota-se que a descrença se deve ao fato do tratamento não se dar em ambiente fechado, para a criança ou o adolescente ficar internado, o que nos remonta à época do Código de Menores, conforme já mencionado por Faleiros e Faleiros (2008) e Oliveira (2010), cuja lógica era o isolamento dos considerados "desviantes", reduzindo indigentes, abandonados e doentes à categoria de "assistidos sociais", o que é intolerável para uma política de proteção aos direitos de crianças e de adolescentes. Mais intolerável ainda é o uso do termo menor, como pode ser visto nas falas, confirmando o que Scheinvar (2009) afirma: as instituições de proteção dos direitos das crianças e dos adolescentes têm tido práticas que violam direitos, práticas essas baseadas no Código de Menor de 1979 (Lei No 6.697, 1979).

A falta de formação dos atores sociais, a falta de conhecimentos sobre a legislação que regulamenta a infância e adolescência, a falta de articulação com as instituições que compõem a Rede para esclarecimento sobre qual a função de cada uma, são todas demandas 
dos atores sociais. Sobre essa questão, Ferreira (2011) destaca que a qualidade dos serviços socioassistenciais disponibilizados à sociedade depende da estruturação do trabalho, da qualificação e da valorização dos profissionais. Além disso, a autora recomenda que sejam previstos, nas esferas federal, estaduais e municipais, recursos no orçamento, especialmente para o desenvolvimento, a qualificação e a capacitação dos profissionais, de forma sistemática, continuada, sustentável, participativa, nacionalizada e descentralizada, com a possibilidade de supervisão integrada, visando ao aperfeiçoamento da prestação dos serviços socioassistenciais.

As Normas Operacionais Básicas definem a composição das equipes que deverão compor a política de assistência social, assim como deverão ser destinados recursos para capacitação e concursos públicos para contratação de mais profissionais; no entanto, a realidade tem sido bem diferente do que está previsto.

Tal fato nos remete ao que Yamamoto e Oliveira (2010) afirmam sobre a precarização das políticas públicas, influenciada pela política neoliberal. Há um enfraquecimento dessas políticas e uma fragmentação das mesmas, com a má qualificação das equipes e o pouco recurso destinado para as instituições (Faraj, \& Siqueira, 2012; Macedo, \& Conceição, 2017; Macedo et al., 2015; Morais et al., 2016; Schek et al., 2018). Isso repercute de forma negativa nos serviços oferecidos à população, limitando-se, desta forma, a quantidade de sujeitos que possam ser atendidos e a qualidade dos serviços, que também é inferior.

Há de se destacar as instituições que relataram ter uma equipe multidisciplinar, como de fundamental importância para o oferecimento de serviços de qualidade; afinal, conseguiam solucionar grande parte das demandas que chegavam até a instituição. Esses dados também foram encontrados por outros autores (Faleiros, \& Faleiros, 2001; Faraj et al., 2016; Rizzini, 2006).

A falta de recursos suficientes, juntamente com a infraestrutura precária, a falta de profissionais em quantidade e a qualificação são fatores que comprometem a eficácia das políticas públicas relacionadas à infância e à adolescência, no que tange à resolução de casos que chegam até as instituições. Soma-se a isso a seleção dos casos a serem encaminhados para a Rede, a partir da crença dos atores sociais sobre sua resolutividade. Tal fato nos leva a pensar numa garantia de direitos somente a nível teórico, já que as práticas das instituições têm o caráter assistencialista, caritativo e higiênico, além de um Estado que tem se isentado de suas funções.

\section{Conclusão}

A partir da análise realizada, foi possível identificar um conceito de Rede como se fosse uma instituição à parte, uma estrutura, que tivesse a função de fazer os acompanhamentos dos casos. Não podemos nos omitir de fazer uma crítica: ao se conceber a Rede como uma instituição, demonstra-se o desconhecimento com as orientações e as normas da política de assistência social e mesmo com o ECA, os quais trazem as diretrizes sobre o funcionamento das políticas de assistência social no nosso país. Esquece-se, porém, que, para ser Rede, é necessária uma atuação em conjunto, onde haja troca de informações, articulação, objetivos comuns, embasamento teórico e um olhar crítico para efetivação das políticas sociais.

A partir dos dados, percebe-se que a Rede de proteção tem tido muitas dificuldades para ser uma ferramenta das políticas públicas no que tange à proteção dos direitos das crianças e dos adolescentes, e ajudar na construção da esfera pública como espaço da consolidação dessas políticas.

As instituições e a Rede como um todo se encontram alijadas dos debates na construção de uma política intersetorial de prevenção da violação dos direitos e de proteção das crianças e dos adolescentes, pois os atores sociais e as instituições não têm formação no que tange nem aos aspectos da própria legislação, muito menos sobre a implementação de políticas.

Não se trata aqui de responsabilizar os atores sociais, mas percebe-se que alguns aspectos - como o não entendimento da lei e as diversas interpretações que a ela são dadas, os estereótipos e estigmas com que ainda são tratados as crianças e os adolescentes, a ausência de capacitação que promova mudanças de perspectivas, a falta de um posicionamento crítico-político, assim como a não interação entre os atores sociais - têm contribuído para uma atuação de forma desencontrada e uma Rede fragilizada. Temos uma Rede em que não há nós, que não possibilita os encontros e as trocas, mas há fios soltos, que não se conectam.

Apesar do avanço nos paradigmas legais e da elaboração de políticas públicas que têm por princípio a dignidade humana, isso não é suficiente para garantir a proteção das crianças e dos adolescentes, se os 
paradigmas compartilhados por quem faz a Rede não forem os mesmos. Mesmo que haja o discurso da proteção, se as práticas estiverem arraigadas sob a ótica repressiva, não se garante o direito.

Há de se considerar que esses resultados se referem à uma cidade de médio porte e não é a rea- lidade de toda a Rede de proteção. Se identifica a necessidade de outras pesquisas, em outras cidades da região, sobre a Rede de proteção e as práticas dos atores sociais das mesmas, bem como a percepção e conhecimento dos atores sociais sobre infância, adolescência, legislação, entre outros aspectos.

\section{Referências}

Alberto, M. F. P., Silva, A. C. S., Gomes, V. C., Santana, R. V. M., \& Soares, A. M. (2012). Os agentes sociais da rede de proteção e atendimento no enfrentamento da exploração sexual comercial. Psicologia: Reflexão e Crítica, 25(1), 1-9. https://doi.org/10.1590/S0102-79722012000100016

Aragão, A. S. (2011). Rede de proteção social e promoção de direitos: Contribuições do conselho tutelar para a integralidade e a intersetorialidade. (Tese de Doutorado). Universidade de São Paulo, São Paulo, SP, Brasil.

Bardin, L. (2010). Análise de conteúdo. Lisboa: 70.

Behring, E. R., \& Boschetti, I. (2011). Política social: Fundamentos e história (9a ed.). São Paulo, SP: Cortez.

Caravieri, L., \& Avoglia, H. R. C. (2016). A rede social e assistencial e a garantia de direitos: Proteção ou (re)vitimização? Psicólogo informação, 20(20), 99-112. https://doi.org/10.15603/2176-0969/pi.v20n20p99-112

Cruz, L. R., \& Guareshi, N. (2012). A constituição da assistência social como política pública: Interrogações à psicologia. In: L. R. Cruz, \& N. Guareshi (Orgs.), Políticas públicas e assistência social: Diálogos com as práticas psicológicas (3a ed., pp. 13-40). Petrópolis, RJ: Vozes.

Faleiros, V. P. (2011). Infância e o processo político no Brasil. In: I. Rizzini, \& F. Pilotti (Orgs.), A arte de governar crianças: A história das políticas sociais, legislação e da assistência à infância no Brasil (pp. 33-96). São Paulo, SP: Cortez.

Faleiros, V. P., \& Faleiros, E. S. (2001). Circuito e curtos circuitos: Atendimento, defesa e responsabilidade do abuso sexual contra crianças e adolescentes no Distrito Federal. São Paulo, SP: Veras.

Faleiros, V. P., \& Faleiros, E. S. (2008). Escola que protege: Enfrentando a violência contra crianças e adolescentes (2a ed.). Brasília, DF: Ministério da Educação.

Faraj, S. P., \& Siqueira, A. C. (2012). O atendimento e a rede de proteção da criança e dos adolescentes vítima de violência sexual na perspectiva dos profissionais do CREAS. Barbarói, (37), 67-87. https://doi.org/10.17058/barbaroi.v0i37.2097

Faraj, S. P., Siqueira, A. C., \& Arpini, D. M. (2016). Rede de proteção: O olhar de profissionais do sistema de garantia de direitos. Temas em Psicologia, 24(2), 727-741. https://doi.org/10.9788/TP2016.2-18

Ferreira, S. S. (2011). NOB-RH anotada e comentada. Brasília, DF: Ministério da Saúde.

Habigzang, L. F, Azevedo, G. A., Koller, S. H., Machado, P. X. (2006). Fatores de risco e de proteção na rede de atendimento a crianças e adolescentes vítimas de violência sexual. Psicologia: Reflexão e Crítica, 19(3), 379-386. https:// doi.org/10.1590/S0102-79722006000300006

Lei No 6.697, de 10 de outubro de 1979. Institui o código de menores. Diário Oficial da União, 11 out. 1979.

Lei No 8.069, de 13 de julho de 1990. Dispõe sobre o estatuto da criança e do adolescente e dá outras providências. Diário Oficial da União, 14 jul. 1990.

Macedo, E. O. S., \& Conceição, M. I. G. (2017). Atendimento psicossocial à crianças e adolescentes em situação de violência: O psicólogo e a rede de atenção. Pesquisas e Práticas Psicossociais, 12(1), 129-146.

Macedo, J. P., \& Dimenstein, M. (2012). O trabalho dos psicólogos nas políticas sociais no Brasil. Avances en Psicologia Latinoamericana, 30(1), 182-192.

Macêdo, O. J., Pessoa, M. C. B., \& Alberto, M. F. P. (2015). Atuação dos profissionais de psicologia junto à infância e à adolescência nas políticas públicas de assistência social. Psicologia: Ciência e Profissão, 35(3), 916-931. https:// doi.org/10.1590/1982-3703000922014 
Marques, E. C. (2006). Redes sociais e poder no estado brasileiro: Aprendizados a partir de políticas urbanas. Revista Brasileira de Ciências Sociais, 21(60), 15-41. https://doi.org/10.1590/S0102-69092006000100002

Marteleto, R. M. (2001). Análise de redes sociais: Aplicação nos estudos de transferência da informação. Ciência da Informação, 30(1), 71-81. https://doi.org/10.1590/S0100-19652001000100009

Morais, R. G. L., Sales, Z. N., Rodrigues, V. P., \& Oliveira, J. S. (2016). Ações de proteção a crianças e adolescentes em situação de violência. Revista de Pesquisa: Cuidado é Fundamental Online, 8(2), 4472-4486. https://doi. org/10.9789/2175-5361.2016.v8i2.4472-4486

Oliveira, I. F., \& Yamamoto, O. H. (2014). Definindo o campo de estudo: As políticas sociais brasileiras. In: I. F. Oliveira, \& O. H. Yamamoto (Orgs.), Psicologia e políticas sociais: Temas em debate (pp. 21-46). Belém, PA: Universidade Federal do Pará.

Oliveira, R. C. S. (2010). Quero voltar para casa: O trabalho em rede e a garantia do direito à convivência familiar e comunitária para crianças e adolescentes que vivem em abrigo (2a ed.). São Paulo, SP: Associação dos Assistentes Sociais e Psicólogos do Tribunal de Justiça do Estado de São Paulo.

Ramidoff, M. L. (2007). Direito da criança e do adolescente: Por uma propedêutica jurídico protetiva transdiciplinar. (Tese de Doutorado). Universidade Federal do Paraná, Curitiba, PR, Brasil.

Reis, C. \& Guareschi, N.M.F. (2016) Nas teias da "rede de proteção": internação compulsória de crianças e adolescentes e a judicialização da vida. Fractal: Revista de Psicologia, 28(1), 94-101. http://dx.doi.org/10.1590/19840292/1143

Resolução no 113 , de 19 de abril de 2006. Dispõe sobre os parâmetros para a institucionalização e fortalecimento do sistema de garantia dos direitos da criança e do adolescente. Diário Oficial da União, 20 abr. 2006. Recuperado de http:// www.sdh.gov.br/sobre/participacao-social/conselho-nacional-dos-direitos-da-crianca-e-do-adolescente-conanda

Rizzini, I. (Coord.). (2006). Acolhendo crianças e adolescentes: Experiências de promoção do direito à convivência familiar e comunitária no Brasil (2a ed.). São Paulo, SP: Cortez.

Rizzini, I. (2011). Crianças e menores: Do pátrio poder ao pátrio dever um histórico da legislação para a infância no Brasil. In: I. Rizzini, \& F. Pilotti, (Orgs.), A arte de governar crianças: A história das políticas sociais, da legislação e da assistência à infância no Brasil (pp. 97-151). São Paulo, SP: Cortez.

Rizzini, I., \& Pilotti, F. (Orgs.). (2011). A arte de governar crianças: A história das políticas sociais, da legislação e da assistência à infância no Brasil (3a ed.). São Paulo, SP: Cortez.

Rizzini, I., \& Rizzini, I. (2004). A institucionalização de crianças no Brasil: Percurso histórico e desafios do presente. São Paulo, SP: Loyola.

Rosemberg F., \& Mariano, C. L. S. (2010). A convenção internacional sobre os direitos da criança: Debates e tensões. Cadernos de Pesquisa, 40(141), 693-728. https:// doi.org/10.1590/S0100-15742010000300003

Scheinvar, E. (2009). O feitiço da política pública: Escola, sociedade civil e direitos da criança e do adolescente. Rio de Janeiro, RJ: Lamparina.

Schek, G., Silva, M. R. S., Lacharité, C., Cézar-Vaz, M. R., Bueno, M. E., \& Ventura, J. (2018). Práticas profissionais que silenciam a violência intrafamiliar contra crianças e adolescentes. Texto \& Contexto: Enfermagem, 27(1), 1-8. https://doi.org/10.1590/0104-07072018001680016

Scisleski, A. C. C. (2006). "Entre se quiser, saia se puder": O percurso dos jovens pelas redes sociais e a internação psiquiátrica. (Dissertação de mestrado). Pontifícia Universidade Católica do Rio Grande do Sul, Porto Alegre, RS, Brasil.

Scisleski, A. C. C., \& Maraschin, C. (2012). Redes sociais e internação psiquiátrica: Paradoxos nas políticas de saúde para a juventude. In: L. R. C. Curz, \& N. Guareschi (Orgs.), Políticas públicas e assistência social: Diálogo com as práticas psicológicas (3a ed.). Petrópolis, RJ: Vozes.

Senado Federal. (1988). Constituição da República Federativa do Brasil. Brasília, DF: o autor.

Silva, A. C. S., \& Pereira, J. C. (2013). O trabalho infanto-juvenil na agricultura no município de Tocantinópolis. Trabalho \& Educação, 22(2), 55-69.

Ude, E. W. (2008). Enfrentamento da violência sexual infanto-juvenil e construção de redes sociais. In: E. P. Cunha, E. M. Silva, \& M. A. C. Giovanetti (Orgs.), Enfrentameto à violencia sexaul infanto-juvenil: Expansão do PAIR em Minas Gerais (pp. 30-61). Belo Horizonte, MG: Universidade Federal de Minas Gerais. 
Yamamoto, O. H., \& Oliveira, I. F. (2010). Política social e psicologia: Uma trajetória de 25 anos. Psicologia: Teoria e Pesquisa 26(esp.), 9-24. https://doi.org/10.1590/S0102-37722010000500002

Ana Cristina Serafim da Silva

Professora do Curso de Psicologia da Universidade Federal do Tocantins (UFT), Miracema - TO. Brasil.

E-mail: anacris_serafim@uft.edu.br

(iD) https://orcid.org/0000-0002-7821-7766

Maria Fátima Pereira Alberto

Professora do Curso de Psicologia da Universidade Federal da Paraíba, Programa de Pós-Graduação em Psicologia Social, UFPB, João Pessoa

E-mail: jfalberto89@gmail.com

(iD https:// orcid.org/0000-0003-2515-9571

Endereço para envio de correspondência:

406 Norte, Alameda 10, Lote 01, Ed. Saint George, Cep 77006-492, Palmas, TO

Recebido 15/09/2017

Aceito 10/09/2018

Received 09/15/2017

Approved 09/10/2018

Recibido 15/09/2017

Aceptado 10/09/2018

Como citar: Silva, Ana Cristina Serafim da, \& Alberto, M. F. (2019). Fios soltos da rede de proteção dos direitos das crianças e adolescentes. Psicologia: Ciência e Profissão, 39, 1-13. https://doi.org/10.1590/1982-3703003185358

How to cite: Silva, Ana Cristina Serafim da, \& Alberto, M. F. (2019). Loose yarn of the network for the protection of children and adolescents' rights. Psicologia: Ciência e Profissão, 39, 1-13 https://doi.org/10.1590/1982-3703003185358

Cómo citar: Silva, Ana Cristina Serafim da, \& Alberto, M. F. (2019). Hilos sueltos de la red de protección de los derechos de los niños y adolescentes. Psicologia: Ciência e Profissão, 39, 1-13. https://doi.org/10.1590/1982-3703003185358 